\title{
Optimizing the Combination of Smoking and Boiling on Quality of Korean Traditional Boiled Loin ( $M$. longissimus dorsi)
}

\author{
Yun-Sang Choi ${ }^{1}$, Hyun-Wook Kim², Ko-Eun Hwang, Dong-Heon Song, Yong-Jae Kim, \\ Tae-Jun Jung, Young-Boong Kim ${ }^{1}$, and Cheon-Jei Kim \\ Department of Food Science and Biotechnology of Animal Resources, Konkuk University, Seoul 143-701, Korea \\ ${ }^{I}$ Food Processing Research Center, Korean Food Research Institute, Seongnam 463-746, Korea \\ ${ }^{2}$ Meat Science and Muscle Biology Lab, Purdue University, West Lafayette, IN 47907, USA
}

\begin{abstract}
The combined effects of smoking and boiling on the proximate composition, technological quality traits, shear force, and sensory characteristics of the Korean traditional boiled loin were studied. Cooking loss, processing loss, and shear force were lower in the smoked/ boiled samples than those in the control (without smoking treatment) $(p<0.05)$. The results showed that the boiled loin samples between the control and treatment did not differ significantly in protein, fat, or ash contents, or $\mathrm{pH}$ values $(p>0.05)$. The treated samples had higher score for overall acceptability than the control $(p<0.05)$. Thus, these results show that the Korean traditional boiled loin treated with smoking for $60 \mathrm{~min}$ before boiling had improved physicochemical properties and sensory characteristics.
\end{abstract}

Key words: smoking, boiling, sensory properties, combination, quality characteristics

Received September 9, 2014 / Revised November 19, 2014 / Accepted November 25, 2014

\section{Introduction}

Traditional Korean boiled pork is simmered with garlic, ginger onion, and leek and is one of the most popular foods in Korea (Kim, 1995; Moon, 2002). Boiled pork has been served at family events for a long time (Choi et al., 2006). Some studies have been conducted on Korean boiled pork. Chae and Kim (2010) reported that textural properties and sensory quality of boiled pork improve using different cooking methods. Choi et al. (2006) found that boiled pork loin using a tumbling method improved quality. Park and Kwon (1998) indicated that the sensory characteristics and tenderness of boiled beef were enhanced by adding bark. They reported that boiled beef made with $5 \%$ bark powder has decreased cooking loss and improved sensory properties. Jung et al. (2004) reported the effects of carcass grade and adding mugwort powder on boiled pork quality. Their results showed that water holding capacity, 2-thiobarbituric acid reactive substance values, and residual nitrite in boiled pork with added mugwort powder were lower than those of boiled

*Corresponding author: Cheon-Jei Kim, Department of Food Science and Biotechnology of Animal Resources, Konkuk University, Seoul 143-701, Korea. Tel: +82-2-450-3684, Fax: +822-444-6695, E-mail: kimcj@konkuk.ac.kr pork without added mugwort powder. However, the boiled meat had poor sensory properties; thus, it is necessary to promote consumer acceptability by improving flavor and textural attributes (Choi, 2005).

Smoking meat products is one of the most ancient food technologies which have been used for food preservation (Djinovic et al., 2008). In general, smoke develops in an external generator under controlled conditions of temperature and air access. Smoking methods are divided according to smoking temperature; the cold-smoking process uses $15-30^{\circ} \mathrm{C}$ (relative humidity: $75-85 \%$ ), the hot smoking process uses $30-50^{\circ} \mathrm{C}$ (relative humidity: 50$70 \%$ ), and the high temperature smoking process uses 50 $80^{\circ} \mathrm{C}$ (relative humidity: $40-50 \%$ ). Smoking technology uses the special effects of diverse sensory active compounds contained in smoke to aromatize meat products. These compounds are polycyclic aromatic hydrocarbons and their alkylated derivatives. Thus, smoked meat products are a significant part of the human diet because of their excellent taste, high nutritional value, and large variety of available products (Kim et al., 2014). Stolyhwo and Sikorski (2005) reported that smoke composition and processing conditions affect sensory quality, shelf life, and wholesomeness of the product. Several studies have been conducted on boiling methods (Chae and Kim, 
2010; Choi et al., 2006; Jung et al., 2004; Park and Kwon, 1998) and smoke treatments (Djinovic et al., 2008; Song et al., 2013; Stolyhwo and Sikorski, 2005). However, research on meat products prepared with a combination of smoking and boiling is limited.

Therefore, the objective of this study was to evaluate the effects of combined smoking and boiling on proximate composition, smoking loss, cooking loss, processing loss, $\mathrm{pH}$, color, shear force, and sensory characteristics of Korean traditional boiled loin.

\section{Materials and Methods}

\section{Preparation and processing}

Fresh pork loin (M. longissimus dorsi) with $70.51 \%$ moisture, $4.78 \%$ fat, $16.38 \%$ protein from castrated boars [Landrace $\times$ Yorkshire $\times$ Duroc] at 5 mon old was purchased 10 from a local processor $48 \mathrm{~h}$ postmortem. All subcutaneous, intramuscular fat and visible connective tissue were removed from the fresh loin muscle. Five different treatments were prepared. The first sample was the control prepared by heat processing in a $100^{\circ} \mathrm{C}$ water bath (model 10-101, Dae Han Co, Korea) until core temperature reached $75^{\circ} \mathrm{C}$ for about $30 \mathrm{~min}$. Then the cooked pork was cooled at $20^{\circ} \mathrm{C}$. The other four samples were prepared by smoking before being boiled. The samples were smoked in a smoke chamber (Model MAXi3501, Kerres, Germany) continually at $65^{\circ} \mathrm{C}$ (relative humidity: $50 \%$ ) for $15,30,60$, or 90 min respectively. The smoke treatment included a smoke chamber and oak wood chips. The smoked samples were heat processed in a $100^{\circ} \mathrm{C}$ water bath until a $75^{\circ} \mathrm{C}$ core temperature was reached. Then the cooked Korean traditional boiled loin was cooled at $20^{\circ} \mathrm{C}$. This procedure was performed in triplicate for each sample, and all analyses were carried out at least in triplicate for each formulation.

\section{Proximate composition}

Composition properties of the samples were determined using AOAC methods (2007). Moisture content (950.46B) was calculated by weight loss after $18 \mathrm{~h}$ of drying at $105^{\circ} \mathrm{C}$ in a drying oven (SW-90D, Sang Woo Scientific Co., Korea). Fat content (960.69) was determined by the Soxhlet method with a solvent extraction system (Soxtec Avanti 2050 Auto System, Foss Tecator AB, Sweden), and protein content (981.10) was determined by the Kjeldahl method with an automatic Kjeldahl nitrogen analyzer (Kjeltec 2300Analyzer Unit, Foss Tecator AB). The nitrogen conversion factor was 6.25. Ash content was determined according to the AOAC method 923.93 (muffle furnace).

\section{Purge loss}

Smoking loss, cooking loss, and processing loss were determined on Korean traditional boiled loin by calculating the weight differences for pork loin before and after smoking and cooking as follows:

Smoking loss $(\%)=($ raw weight - smoked weight $) /$ raw weight $\times 100$

Cooking loss $(\%)=($ smoked weight - cooked weight $) /$ smoked weight $\times 100$

Processing loss $(\%)=$ smoking loss + cooking loss

pH

The $\mathrm{pH}$ values of sample were measured in a homogenate prepared with $5 \mathrm{~g}$ of sample and distilled water (20 $\mathrm{mL}$ ) using a $\mathrm{pH}$ meter (Model 340, Mettler-Toledo $\mathrm{GmbH}$, Switzerland). The $\mathrm{pH}$ meter calibrated with standard 4.00, 7.02, and $10.05 \mathrm{pH}$ buffers (VWR Scientific Products) at a temperature of $20 \pm 1^{\circ} \mathrm{C}$. All determinations were performed in triplicate.

\section{Color}

The color of each sample was determined using a colorimeter (Minolta Chroma meter CR-210, Minolta Ltd., Japan; illuminate C, calibrated with a white plate, $L^{*}=$ $+97.83, a^{*}=-0.43$, and $b^{*}=+1.98$ ). Seven measurements for each sample of five replicates were obtained. CIE $L^{*}$ (lightness), CIE $a^{*}$ (redness), and CIE $b^{*}$ (yellowness) values were recorded.

\section{Warner-Bratzler shear force (WBSF)}

The Warner-Bratzler shear force was measured at room temperature using a texture analyzer (TA-XT2 $i$, Stable Micro Systems Ltd., England) according to the method of Hong et al. (2008). The cooked samples were cooled at room temperature for $30 \mathrm{~min}$. The samples were allowed to equilibrate to room temperature. Each sample was cut with a knife into length $\times$ width: $3 \times 4 \mathrm{~cm}$ sections and the sections were sheared in separate locations with Warner-Bratzler blade set attached to a texture analyzer. The Warner-Bratzler head moved at a crosshead speed of $200 \mathrm{~mm} / \mathrm{min}$. Data were collected and analyzed from Warner-Bratzler shear force values to obtain for the maximum force required to shear through each sample and 
was then converted into $\mathrm{kg}$.

\section{Sensory evaluation}

The sensory evaluations were performed in triplicate on each sample by trained sensory panelist. A selected twelvemember panel consisting of researchers from the Department of Food Sciences and Biotechnology of Animal Resources at Konkuk University in Korea was used to evaluate the cooked samples. Selection of panelists was performed according to sensory evaluation procedure (Lawless and Heymann, 1999). Each cooked sample was evaluated in terms of color, flavor, juiciness, tenderness, and overall acceptability. The cooked samples were cut into quarters (length $\times$ width: $3 \times 4 \mathrm{~cm}$ ), and served randomly to the panelists. Each sample was coded with a randomly selected 3-digit number. Sensory evaluations were performed under fluorescent lighting. Panelists were instructed to cleanse their palates with water between samples. The color $(1=$ extremely undesirable, $10=$ extremely desirable), flavor ( 1 = extremely undesirable, 10 = extremely desirable $)$, tenderness $(1=$ extremely tough, $10=$ extremely tender $)$, juiciness $(1=$ extremely dry, $10=$ extremely juicy), and overall acceptability ( $1=$ extremely undesirable, 10 = extremely desirable) of the cooked samples were evaluated using a 10-point descriptive scale. This analysis was conducted using the hedonic test described by Bergara-Almeida and da Silva (2002).

\section{Statistical analysis}

The experiments were replicated three times, and values represent the mean and standard. Analysis of variance (proximate composition, smoking loss, cooking loss, processing loss, $\mathrm{pH}$, color, WBSF, and sensory evaluation) was conducted using the general linear model (GLM) procedure of the SAS statistical package (2008). Duncan's multiple range tests $(p<0.05)$ was used to determine the differences among treatments.

\section{Results and Discussion}

\section{Proximate composition}

The proximate composition of the Korean traditional boiled loin treated by combined smoking and boiling is shown in Table 1. The highest moisture contents were observed in the 60 and 90 min smoke treated samples before being boiled ( $\mathrm{S} 60$ and S90) compared to that in the other treatments $(p<0.05)$. These contrasting results could be attributed due to the increased moisture content during smoking, which is caused by a hard coating that forms on the meat surface and reduces cooking loss (Table 2). Chae and Kim (2010) reported that high temperature and long cooking time produces lower moisture content in boiled pork. According to Chae (2011), the moisture content in boiled pork is influenced by cooking methods such as boiling and steaming. However, Hyon et al. (2003) reported that the effects of curing temperature and time on moisture content of cured boiled pork loin did not differ significantly among treatments. Protein, fat, and ash contents were not significantly different between the control without smoking and those of samples that were smoked $(p>0.05)$.

\section{Purge loss}

Table 2 shows smoking loss, cooking loss, and processing loss in Korean traditional boiled loin treated with combined smoking and boiling. Smoking loss increased significantly by increasing smoking time $(p<0.05)$. Cooking loss of the pork loin was lower for treatments treated with combined smoking and boiling than that of the control $(p<0.05)$. The highest processing loss was in the control compared to that in the combined smoking and boiling treatment $(p<0.05)$, but it did not differ significantly among all treatments $(p>0.05)$. According to Pan and Singh (2001), cooking loss in cooked meat products increases as heating temperature increases. Chae (2011)

Table 1. Effect of smoking period on proximate composition of Korean traditional boiled loin treated with a combination of smoking and boiling (Units: \%)

\begin{tabular}{cccccc}
\hline \hline Parameters & Control $^{\mathrm{I}}$ & \multicolumn{1}{c}{ S15 } & S30 & S60 & S90 \\
\hline Moisture content & $62.12 \pm 0.24^{\mathrm{B}}$ & $62.85 \pm 0.31^{\mathrm{B}}$ & $63.38 \pm 0.48^{\mathrm{AB}}$ & $64.57 \pm 0.70^{\mathrm{A}}$ & $64.05 \pm 0.42^{\mathrm{A}}$ \\
Protein content & $26.32 \pm 0.45$ & $27.31 \pm 0.32$ & $27.45 \pm 0.42$ & $27.67 \pm 0.31$ & $27.75 \pm 0.25$ \\
Fat content & $3.21 \pm 0.14$ & $3.17 \pm 0.13$ & $3.16 \pm 0.12$ & $3.19 \pm 0.14$ & $3.18 \pm 0.11$ \\
Ash content & $3.43 \pm 0.84$ & $3.01 \pm 0.51$ & $3.49 \pm 0.61$ & $3.34 \pm 0.85$ & $3.18 \pm 0.24$ \\
\hline
\end{tabular}

All values are mean \pm standard deviation of three replicates.

${ }^{\mathrm{A}, \mathrm{B}}$ Means within a row with different letters are significantly different $(p<0.05)$.

${ }^{1)}$ Control: pork loin without smoking before boiling, S15: pork loin treated with a combination of smoking for 15 min and boiling, S30: pork loin treated with a combination of smoking for $30 \mathrm{~min}$ and boiling, S60: pork loin treated with a combination of smoking for 60 min and boiling, S90: pork loin treated with a combination of smoking for $90 \mathrm{~min}$ and boiling. 
Table 2. Effect of smoking period on purge loss of Korean traditional boiled loin treated with a combination of smoking and boiling (Units: \%)

\begin{tabular}{cccccc}
\hline \hline Parameters & Control $^{\text {I) }}$ & S15 & S30 & S60 & S90 \\
\hline Smoking loss & - & $10.76 \pm 0.98^{\mathrm{D}}$ & $12.11 \pm 0.56^{\mathrm{C}}$ & $14.44 \pm 0.92^{\mathrm{B}}$ & $16.03 \pm 0.89^{\mathrm{A}}$ \\
Cooking loss & $34.85 \pm 4.31^{\mathrm{A}}$ & $19.20 \pm 4.53^{\mathrm{B}}$ & $17.03 \pm 4.61^{\mathrm{B}}$ & $11.45 \pm 4.77^{\mathrm{C}}$ & $12.73 \pm 5.80^{\mathrm{C}}$ \\
Processing loss & $34.85 \pm 4.31^{\mathrm{A}}$ & $29.96 \pm 4.68^{\mathrm{B}}$ & $29.13 \pm 4.70^{\mathrm{B}}$ & $25.88 \pm 5.50^{\mathrm{B}}$ & $28.76 \pm 6.20^{\mathrm{B}}$ \\
\hline
\end{tabular}

All values are mean \pm standard deviation of three replicates.

${ }^{\text {A-D }}$ Means within a row with different letters are significantly different $(p<0.05)$.

${ }^{1)}$ Control: pork loin without smoking before boiling, S15: pork loin treated with a combination of smoking for 15 min and boiling, S30: pork loin treated with a combination of smoking for $30 \mathrm{~min}$ and boiling, S60: pork loin treated with a combination of smoking for 60 min and boiling, S90: pork loin treated with a combination of smoking for $90 \mathrm{~min}$ and boiling.

Table 3. Effect of smoking period on pH of Korean traditional boiled loin treated with a combination of smoking and boiling

\begin{tabular}{cccccc}
\hline \hline Parameters & Control ${ }^{1}{ }^{1}$ & S15 & S30 & S60 & S90 \\
\hline Raw meat & $5.86 \pm 0.21$ & $5.81 \pm 0.24$ & $5.82 \pm 0.22$ & $5.81 \pm 0.25$ & $5.79 \pm 0.24$ \\
After smoking & - & $5.90 \pm 0.21$ & $5.91 \pm 0.24$ & $5.94 \pm 0.19$ & $5.93 \pm 0.23$ \\
After boiling & $6.28 \pm 0.18$ & $6.12 \pm 0.20$ & $6.18 \pm 0.21$ & $6.14 \pm 0.26$ & $6.17 \pm 0.24$ \\
\hline
\end{tabular}

All values are mean \pm standard deviation of three replicates.

${ }^{1)}$ Control: pork loin without smoking before boiling, S15: pork loin treated with a combination of smoking for 15 min and boiling, S30: pork loin treated with a combination of smoking for $30 \mathrm{~min}$ and boiling, S60: pork loin treated with a combination of smoking for 60 min and boiling, S90: pork loin treated with a combination of smoking for $90 \mathrm{~min}$ and boiling.

indicated that cooking loss in boiled pork increases as the periods of boiling and steaming increase. Pöhlmann et al. (2012) found that purge loss from lightly smoked sausages was higher as a result of longer smoking time. Also, Kim et al. (2014) indicated that hot smoke processed sausages show decreased cooked yield, and the cooking loss of the smoked treatments was higher than that of the other treatments. These results seem to indicate that processing loss from smoked treatments is lower, which is affected by the smoke coating formed on the pork meat surface because the moisture contained in the meat is not released.

\section{pH and color}

The $\mathrm{pH}$ of Korean traditional boiled loin treated with combined smoking and boiling is shown Table 3. The $\mathrm{pH}$ was not significantly different between the control and the combined smoking and boiling treatment $(p>0.05)$. Smoking did not significantly influence the $\mathrm{pH}$ value of pork loin. However, $\mathrm{pH}$ of the smoke-treated samples was higher than that in before smoking, but treatments after cooking had an increased $\mathrm{pH}$. These results agree with those reported by Choi et al. (2009), who found that the $\mathrm{pH}$ of meat products increases with heating due to the imidazolium that is unfolded and exposed and has basic activity due to high histidine content. Jeon et al. (1995) reported that $\mathrm{pH}$ of bacon is not affected by smoking temperature.

The statistical results indicated that the color parame- ters of the Korean traditional boiled loin were affected by smoking and boiling (Table 4). The CIE $L^{*}$ (lightness) value of the treatments after smoking increased with an increase in smoking period ( $p>0.05)$, whereas the lightness values after boiling decreased by increasing the smoking time ( $p>0.05$ ). The CIE $a^{*}$ (redness) and the CIE $b^{*}$ (yellowness) values of treatments before they were boiled tended to increase slightly by increasing the smoking period. The redness and yellowness values of samples after boiling increased as the smoking period increased. A study by Kim et al. (2014) reported increased lightness and decreased yellowness of cooked sausages treated with/without smoking. Pöhlmann et al. (2012) indicated that lightly smoked meat products are less colored than medium and intensively smoked meat products, and the lightness value of lightly smoked meat products was higher than of intensively smoked meat products. Chae and Kim (2010) reported that the instrumental color of Korean boiled pork was different based on cooking conditions.

\section{Shear force}

The effects of smoking and boiling on shear force of the Korean traditional boiled loin are shown in Fig. 1. The highest shear force was in the control, whereas the lowest shear force was in the pork loin treated with 60 or 90 min of smoking followed by boiling (S60 and S90). Chae and Kim (2010) reported that the effects of various cooking conditions on shear force of boiled pork were 
Table 4. Effect of smoking period on color values of Korean traditional boiled loin treated with a combination of smoking and boiling

\begin{tabular}{ccccc}
\hline \hline & Parameters & Raw meat & After smoking & After boiling \\
\hline & Control ${ }^{1)}$ & $51.19 \pm 2.73$ & - & $65.88 \pm 2.23^{\mathrm{AB}}$ \\
CIE $L^{*}$ & S15 & $51.97 \pm 3.17$ & $49.23 \pm 1.62^{\mathrm{B}}$ & $66.39 \pm 1.84^{\mathrm{A}}$ \\
& S30 & $52.05 \pm 2.60$ & $49.58 \pm 1.59^{\mathrm{AB}}$ & $64.72 \pm 1.31^{\mathrm{B}}$ \\
& S60 & $51.56 \pm 2.62$ & $50.00 \pm 1.66^{\mathrm{AB}}$ & $62.15 \pm 1.21^{\mathrm{C}}$ \\
& S90 & $52.15 \pm 2.53$ & $50.90 \pm 2.18^{\mathrm{A}}$ & $59.48 \pm 1.50^{\mathrm{D}}$ \\
\hline & Control & $14.49 \pm 0.92$ & - & $5.43 \pm 0.58^{\mathrm{D}}$ \\
CIE $a^{*}$ & S15 & $14.47 \pm 1.19$ & $13.63 \pm 1.31^{\mathrm{B}}$ & $5.85 \pm 0.55^{\mathrm{CD}}$ \\
& S30 & $14.58 \pm 0.88$ & $13.63 \pm 1.14^{\mathrm{B}}$ & $6.26 \pm 0.54^{\mathrm{C}}$ \\
& S60 & $14.43 \pm 0.84$ & $14.48 \pm 1.19^{\mathrm{AB}}$ & $7.27 \pm 0.43^{\mathrm{B}}$ \\
& S90 & $14.33 \pm 1.04$ & $14.84 \pm 1.53^{\mathrm{A}}$ & $8.30 \pm 0.88^{\mathrm{A}}$ \\
\hline & Control & $3.27 \pm 1.42$ & - & $8.14 \pm 0.67^{\mathrm{D}}$ \\
& S15 & $3.10 \pm 1.65$ & $6.19 \pm 1.59^{\mathrm{B}}$ & $10.89 \pm 1.00^{\mathrm{C}}$ \\
& S30 & $3.20 \pm 1.45$ & $6.70 \pm 1.54^{\mathrm{AB}}$ & $12.27 \pm 1.04^{\mathrm{B}}$ \\
& S60 & $3.04 \pm 1.26$ & $7.49 \pm 2.72^{\mathrm{AB}}$ & $13.84 \pm 0.86^{\mathrm{A}}$ \\
\end{tabular}

All values are mean \pm standard deviation of three replicates.

${ }^{\text {A-D }}$ Means within a column with different letters are significantly different $(p<0.05)$.

${ }^{1)}$ Control: pork loin without smoking before boiling, S15: pork loin treated with a combination of smoking for 15 min and boiling, S30: pork loin treated with a combination of smoking for $30 \mathrm{~min}$ and boiling, S60: pork loin treated with a combination of smoking for 60 min and boiling, S90: pork loin treated with a combination of smoking for $90 \mathrm{~min}$ and boiling.

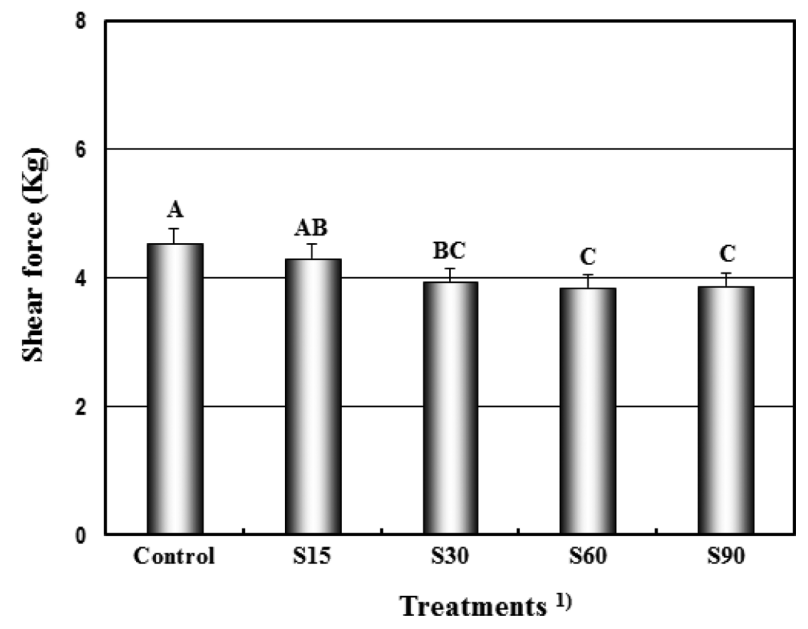

Fig. 1. Effect of smoking period on shear force of Korean traditional boiled loin treated with a combination of smoking and boiling. ${ }^{\mathrm{A}-\mathrm{C}}$ Means in the treatments with different letters are significantly different $(p<0.05)$. ${ }^{1)}$ Control, pork loin without smoking before boiling, S15, pork loin treated with a combination of smoking for $15 \mathrm{~min}$ and boiling, S30, pork loin treated with a combination of smoking for $30 \mathrm{~min}$ and boiling, S60, pork loin treated with a combination of smoking for $60 \mathrm{~min}$ and boiling, S90, pork loin treated with a combination of smoking for $90 \mathrm{~min}$ and boiling.

significant. Choi et al. (2006) showed that tumbling boiled pork loin produces lower shear force than control (without tumbling treatment). According to Kim et al. (2014), smoke processing contributes to increase hardness. Kelle et al. (2004) observed that moist-heat cooked beef steak has lower shear force than that of dry-heat cooked steak, whereas Van Oeckel et al. (1999) found that Warner-Bratzler shear force of meat samples grilled to an internal temperature of $74^{\circ} \mathrm{C}$ was higher than that of steaks boiled at $75^{\circ} \mathrm{C}$ for $50 \mathrm{~min}$. Generally, tenderness is a major quality attribute of a meat product. Thus, Korean traditional boiled loin processed by boiling and smoking was the method to improve tenderness, particularly a 60 or $90 \mathrm{~min}$ smoking time before boiling.

\section{Sensory evaluation}

The sensory traits of the Korean traditional boiled loin treated with smoking and boiling are given in Table 5 . The control samples had the lowest overall sensory trait scores $(p<0.05)$, compared to those of the combined smoking and boiling-treated samples $(p<0.05)$. These results may be due to the smoke treatment. The overall acceptability score was the highest for the combined $60 \mathrm{~min}$ smoking time and boiling ( 600$)(p<0.05)$. These results agree with those reported by Kim et al. (2014), who found that a smoke processing treatment contributed to increase the flavor and overall acceptance satisfaction scores. Similar results were obtained by Park et al. (2010) for the influence of added smoke processing on sensory quality of shark meat. They reported that smoked meat has better taste, color, flavor, appearance, texture, and 
Table 5. Effect of smoking period on sensory properties of Korean traditional boiled loin treated with a combination of smoking and boiling

\begin{tabular}{cccccc}
\hline \hline Parameters & Control $^{1)}$ & S15 & S30 & S60 & S90 \\
\hline Color of appearance & $7.64 \pm 0.67^{\mathrm{D}}$ & $8.36 \pm 0.50^{\mathrm{C}}$ & $8.64 \pm 0.81^{\mathrm{BC}}$ & $8.73 \pm 0.65^{\mathrm{AB}}$ & $8.82 \pm 0.87^{\mathrm{A}}$ \\
Color of internal & $7.63 \pm 0.71^{\mathrm{C}}$ & $8.13 \pm 0.68^{\mathrm{B}}$ & $8.17 \pm 0.64^{\mathrm{B}}$ & $8.29 \pm 0.69^{\mathrm{B}}$ & $8.75 \pm 0.79^{\mathrm{A}}$ \\
Flavor & $7.45 \pm 0.69^{\mathrm{B}}$ & $8.45 \pm 0.82^{\mathrm{A}}$ & $8.82 \pm 0.75^{\mathrm{A}}$ & $8.82 \pm 0.60^{\mathrm{A}}$ & $8.82 \pm 0.75^{\mathrm{A}}$ \\
Smoking flavor & $2.74 \pm 0.91^{\mathrm{C}}$ & $6.00 \pm 1.00^{\mathrm{B}}$ & $7.39 \pm 1.03^{\mathrm{AB}}$ & $8.17 \pm 0.83^{\mathrm{A}}$ & $8.30 \pm 1.22^{\mathrm{A}}$ \\
Tenderness & $7.92 \pm 0.83^{\mathrm{D}}$ & $8.32 \pm 0.78^{\mathrm{C}}$ & $8.45 \pm 0.82^{\mathrm{BC}}$ & $9.09 \pm 0.70^{\mathrm{A}}$ & $8.82 \pm 0.60^{\mathrm{AB}}$ \\
Juiciness & $7.82 \pm 0.87^{\mathrm{C}}$ & $8.41 \pm 0.92^{\mathrm{B}}$ & $8.52 \pm 0.81^{\mathrm{AB}}$ & $9.09 \pm 0.83^{\mathrm{A}}$ & $8.69 \pm 0.80^{\mathrm{A}}$ \\
Overall acceptability & $7.86 \pm 0.45^{\mathrm{D}}$ & $8.41 \pm 0.66^{\mathrm{C}}$ & $8.82 \pm 0.75^{\mathrm{C}}$ & $9.27 \pm 0.65^{\mathrm{A}}$ & $8.73 \pm 0.64^{\mathrm{AB}}$ \\
\hline
\end{tabular}

All values are mean \pm standard deviation of three replicates.

${ }^{\text {A-D }}$ Means within a row with different letters are significantly different $(p<0.05)$.

${ }^{1)}$ Control: pork loin without smoking before boiling, S15: pork loin treated with a combination of smoking for 15 min and boiling, S30: pork loin treated with a combination of smoking for $30 \mathrm{~min}$ and boiling, S60: pork loin treated with a combination of smoking for 60 min and boiling, S90: pork loin treated with a combination of smoking for $90 \mathrm{~min}$ and boiling.

overall acceptability compared to those of a control that was not smoked. Jeon et al. (1995) indicated that wet smoked bacon had higher overall acceptability scores than that of dry smoked bacon. Chae and Kim (2010) reported that the effects of various cooking methods on overall acceptability of boiled pork were significant. However, Montgomery et al. (1977) found that juiciness, tenderness, and overall acceptability was not different when pork loin was heated in a microwave or a conventional oven to an internal temperature of $63^{\circ} \mathrm{C}$. According to Choi et al. (2006), tumbling processing of boiled pork loin results in higher sensory evaluation scores than those of no tumbling pork lion.

\section{Conclusion}

We showed that the combination of smoking and boiling had an important effect on Korean traditional boiled loin quality. Korean traditional boiled loin treated with smoking and boiling had improved processing loss, shear force, and sensory properties. The Korean traditional boiled loin treated with 60 min of smoking followed by boiling had higher overall acceptability than that of the other treatments. Therefore, these results show that pork lion combined smoking for $60 \mathrm{~min}$ and boiling showed the best quality characteristics.

\section{Acknowledgements}

This research was supported High Value added Food Technology Development Program (2014-314068-3) by the Ministry of Agriculture, Food and Rural Affairs (Republic of Korea).
1. AOAC (2007) Official methods of analysis AOAC (18th ed.). Washington, DC: Association of Official Analytical Chemists.

2. Bergara-Almeida, S. and da Silva, M. A. A. P. (2002) Hedonic scale with reference: Performance in obtaining predictive models. Food Qual. Prefer. 13, 57-64.

3. Chae, Y. C. (2011) Cooking optimization of soo-yuk with various cooking methods. Ph.D. thesis, Konkuk Univ., Seoul, Korea.

4. Chae, Y. C. and Kim, C. J. (2010) Effects of various cooking methods on quality characteristics of Korean boiled pork (Soo-yuk). Korean J. Food Sci. An. 30, 42-48.

5. Choi, Y. S. (2005) Physicochemical and sensory characteristics of boiled pork loin as affected by cooking condition, geometric shape and tumbling treatment. MS. thesis, Konkuk Univ., Seoul, Korea.

6. Choi, Y. S., Jeong, J. Y., Choi, J. H., Lee, M. A., Lee, E. S., Kim, H. Y., Han, D. J., Kim, J. M., and Kim, C. J. (2006) Effects of immersion period after tumbling processing on the quality properties of boiled pork loin with soy sauce. Korean J. Food Cookery Sci. 22, 379-385.

7. Choi, Y. S., Choi, J. H., Han, D. J., Kim, H. Y., Lee, M. A., Kim, H. W., and Kim, C. J. (2009) Characteristics of low-fat meat emulsion systems with pork fat replaced by vegetable oils and rice bran fiber. Meat Sci. 82, 266-271.

8. Djinovic, J., Popovic, A., and Jira, W. (2008) Polycyclic aromatic hydrocarbons (PAHs) in different types of smoked meat products from Serbia. Meat Sci. 80, 449-456.

9. Hong, G. P., Kim, C. J., Lee, S., and Min, S. G. (2008) Studies on changes of carcass characteristics during slaughtering process and physical properties of ostrich muscles. Korean $J$. Poult. Sci. 35, 191-196.

10. Hyon, J. S., Kang, H. G., Kim, M. S., Jung, I. C., and Moon, Y. H. (2003) Effects of curing temperature and times on chemical properties and palatability of cured boiled pork loins. Korean J. Food Sci. An. 23, 32-38.

11. Jeon, K. H., Lee, S. K., Yoo, I. J., Kim, Y. B., and Kim, I. H. (1995) Effect of different curing methods and smoking temperature on the shelf-life of bacon. Korean. J. Food Sci. An. 15, 203-209.

12. Jung, I. C., Moon, Y. H., and Kang, S. J. (2004) Effects of

\section{References}


addition of mugwort powder on the physicochemical and sensory characteristics of boiled pork. Korean J. Food Sci. An. 24, 15-22.

13. Lawless, H. T. and Heymann, H. (1999) Sensory evaluation of food: principles and practices. New York: Chapman \& Hall, An Aspen Publication.

14. Kim, H. W., Choi, J. H., Choi, Y. S., Kim, H. Y., Lee, M. A., Hwang, K. E., Song, D. H., Lee, J. W., and Kim, C. J. (2014) Effects of kimchi and smoking on quality characteristics and shelf life of cooked sausages prepared with irradiated pork. Meat Sci. 96, 548-553.

15. Kim, T. H. (1995) Historical study of beef cooking - iv. Boiled beef and sliced of boiled beef. Korean J. Dietary Culture 9, 499-507.

16. Kolle, B. K., McKenna, D. R., and Savell, J. W. (2004) Methods to increase tenderness of individual muscles from beef rounds when cooked with dry or moist heat. Meat Sci. 68, 145-154.

17. Montgomery, T. M., Ramsey, C. B., and Lee, R. W. (1977) Microwave and conventional precooking of hot and cold processed pork loins. J. Food Sci. 42, 310-315.

18. Moon, Y. H. (2002). Effects of adding polyphosphate on the water holding capacity and palatability of boiled pork loin. Korean J. Food Sci. An. 22, 130-136.

19. Pan, Z. and Singh, P. (2001) Physical and thermal properties of ground beef during cooking. LWT-Food Sci. Technol. 34,
437-444.

20. Park, H. J., Park, L. Y., Yoon, K. S., and Lee, S. H. (2010) Quality characteristics of smoked dombaeki (shark meat). Korean J. Food Preserv. 17, 471-477.

21. Park, S. W. and Kwon, S. K. (1998) Sensory characteristics and tenderness of boiled beef by addition of the bark (morus alba Linne). Korean J. Food Nutr. 11, 580-584.

22. Pöhlmann, M., Hitzel, A., Schwägele, F., Speer, K., and Jira, W. (2012) Contents of polycyclic aromatic hydrocarbons (PAH) and phenolic substances in frankfurter-type sausages depending on smoking conditions suing glow smoke. Meat Sci. 90, 176-184.

23. SAS (2008) SAS user's guide: Release 9.2, Basic statistical analysis. Cary, NC, USA: Statistical Analysis Systems Institute.

24. Song, N. B., Song, H. Y., Jo, W. S., and Song, K. B. (2013) Physical properties of a composite film containing sunflower seed meal protein and its application in packaging smoked duck meat. J. Food Engine. 116, 789-795.

25. Stolyhwo, A. and Sikorski, Z. E. (2005) Polycyclic aromatic hydrocarbons in smoked fish - a critical review. Food Chem. 91, 303-311.

26. Van Oeckel, M. J., Warnants, N., and Boucqué, Ch. V. (1999) Pork tenderness estimation by taste panel. Warner-Bratzler shear force and on-line methods. Meat Sci. 53, 259-267. 